\title{
О НЕКОТОРЫХ ОСОБЕННОСТЯХ ФУНКЦИОНИРОВАНИЯ ФЕДЕРАЛЬНОЙ РЕЗЕРВНОЙ СИСТЕМЫ
}

\section{ABOUT SOME FEATURES OF THE FUNCTIONING OF THE FEDERAL RESERVE SYSTEM}

\section{S. Belenchuk \\ V. Nezamaikin}

Summary. The article discusses some of the features of the US Federal Reserve System (Fed, or the Federal Reserve). The Federal Reserve is most often guided in its activities by its own priorities, among which maintaining financial markets is not one of the most important. This happens almost always, except for those historical periods of time when, according to the establishment, the monetary system faces unacceptable risks. At the same time, maintaining a dollar system is always a top priority for the Federal Reserve. With the filing of the Fed, the function of implementing monetary policy was actually taken on by financial companies acting as the so-called primary dealers of the Fed. The list of primary dealers includes mainly structures affiliated with the largest world banks, which are likely to be shareholders of the Fed. Primary dealers are given the opportunity to influence monetary policy through open market operations. The role of primary dealers is also evidenced by the situation in the monetary policy at the beginning of 2019, when, largely based on the interests of primary dealers, the Fed again turned to a policy of reducing key rates after a relatively short period of tightening monetary policy. However, in September 2019, the Federal Reserve was forced to resort to emergency measures to protect the financial system and agree to limit its own independence. These measures became especially intense when the COVID-19 pandemic broke out in the world.

Keywords: Federal reserve system, primary dealers, monetary policy, currency swaps, money supply.

B есьма распространенным упрощением в оценке деятельности Федеральной резервной системы (ФРС, или Федрезерв) является мнение о том, что американский ЦБ автоматически сделает все необходимое для предотвращения падения финансовых рынков. Если же кризисы и случались, то это значило, что никакие усилия ФРС не могли предотвратить их наступление. На самом деле чаще всего Федрезерв руководствуется в своей деятельности собственными приоритетами, среди которых поддержание финансовых рынков не относится к категории самых главных.
Беленчук Сергей Иванович

К.э.н., доцент, Российский государственный гуманитарный университет, Москва

belenchuk51@mail.ru

Незамайкин Валерий Николаевич

Д.э.н., профессор, Российский государственный гуманитарный университет, Москва nezamaikinvn@mail.ru

Аннотация. В статье рассматриваются некоторые особенности деятельности Федеральной резервной системы США (ФРС, или Федерального резерва). Федеральный резерв чаще всего руководствуется в своей деятельности собственными приоритетами, среди которых поддержание финансовых рынков не относится к категории самых главных. Так происходит почти всегда, кроме тех исторических отрезков времени, когда, по оценке истеблишмента, денежно-финансовая система сталкивается с неприемлемыми для себя рисками. В то же время сохранение долларовой системы всегда является важнейшим приоритетом для Федеральной резервной системы. С подачи ФРС функцию реализации кредитно-денежной политики на самом деле взяли на себя финансовые компании, выступающие в качестве так называемых первичных дилеров ФРС. В перечень первичных дилеров входят главным образом структуры, аффилированные с крупнейшими мировыми банками, которые с известной долей вероятности могут являться акционерами ФРС. Первичные дилеры получают возможность воздействовать на кредитно-денежную политику через операции на открытом рынке. 0 роли первичных дилеров свидетельствует и ситуация, сложившаяся в кредитно-денежной политике в начале 2019 года, когда во многом исходя из интересов первичных дилеров ФРС после относительно недолгого периода ужесточения денежной политики вновь обратилась к политике снижения ключевых ставок. Однако в сентябре 2019 год Федрезерв был вынужден прибегнуть к чрезвычайным мерам для защиты финансовой системы и согласиться на ограничение своей независимости. Особой интенсивности эти меры эти меры достигли, когда в мире вспыхнула пандемия КОВИД-19.

Ключевые слова: Федеральная резервная система, первичные дилеры, денежная политика, валютные свопы, денежная масса.

Так происходит почти всегда, кроме тех исторических отрезков времени, когда, по оценке истеблишмента, денежно-финансовая система сталкивается с неприемлемыми для себя рисками - практически рисками распада. В данные исторические отрезки система мобилизуется и сплачивается, оставляя (временно) в стороне противоречия между ФРС и исполнительной властью.

В то же время большую часть времени акционеры ФРС ведут свою собственную игру, согласовывая собственные интересы с интересами американского госу- 
дарства лишь в самой минимальной степени. Это дает основание для ряда американских экспертов высказывать мнение о том, что «цель ФРС - это намеренное и контролируемое уничтожение не только американских рынков, но также и американских долговых инструментов, и доллара» (7). В этом высказывании принципиальное возражение вызывает лишь тезис об уничтожении доллара как одной из целей ФРС, по крайней мере, в рамках того соотношения сил, которое сложилось в ФРС на сегодняшний день. Именно сохранение долларовой системы представляется важнейшим приоритетом для Федеральной резервной системы.

Для оценки деятельности ФРС важным источником может стать публикация «Как ФРС контролирует фондовый рынок», появившаяся на сайте известной американской компании '. В докладе высказывается мысль о том, что Федрезерв имеет неформальные отношения с целой группой наиболее влиятельных мировых финансовых компаний, которые занимаются манипуляциями на финансовых рынках. Более того, составители доклада предполагают, что за кризис 2008 года значительную долю ответственности несет ФРС совместно с упомянутыми компаниями, тогда как одной из главных функций Федрезерва является обеспечение устойчивости доллара и, соответственно, стабильности финансовых рынков (2).

Следовательно, постепенно стала вырисовываться идея о том, что Федрезерв при определенных обстоятельствах вполне в состоянии сыграть роль триггера общенационального кризиса, причем, ряд специалистов полагает, что нечто похожее произошло в 1929 году.

В этой связи важно отметить, что в докладе проводится мысль о том, что с подачи ФРС функцию реализации кредитно-денежной политики на самом деле взяли на себя упомянутые финансовые компании, выступающие в качестве так называемых первичных дилеров (ПД) ФPC ${ }^{2}$.

В перечень ПД входят главным образом структуры, аффилированные с крупнейшими мировыми банками, которые с известной долей вероятности могут являться акционерами ФРС. Об этом, в частности, может свидетельствовать их статус банков-членов Федеральной резервной системы. Кроме того, их руководители входят в руководящие органы региональных банков ФРС. К этому следует добавить, что ПД играют определяющую роль на рынках американских госбумаг. Они же являются ведущими market makers и на других финансовых рынках.

\footnotetext{
"The Sure Money Investor"

2 Primary Dealers
}

В соответствии с последней имеющейся я информацией в список ПД вошли такие компании, как Goldman, Sachs \& Co., Citigroup Global Markets Inc., Merrill Lynch, Pierce, Fenner \& Smith Incorporated, Morgan Stanley \& Co. LLC, Bank of Nova Scotia, New York Agency, Credit Suisse Securities (USA) LLC, BNP Paribas Securities Corp, Deutsche Bank Securities Inc., HSBC Securities (USA) Inc., Barclays Capital Inc., Daiwa Capital Markets America Inc. и некоторые другие (4) ${ }^{3}$. В нем находятся не только американские банки, но банки из Великобритании, Франции, Германии, Швейцарии, Японии, Канады, что соответствует представлениям о том, что среди акционеров ФРС присутствуют и иностранные банки.

ПД получают возможность воздействовать на кредитно-денежную политику через операции на открытом рынке, в рамках которых ФРС либо покупает ценные бумаги у ПД, либо предоставляет им займы. При этом речь идет только о государственных или гарантируемых государством ценных бумагах, что отражает законодательные ограничения для деятельности Федрезерва. Можно предположить после 2008 года вплоть до самого последнего времени Федрезерв покупает ценные бумаги не напрямую, а только через первичных дилеров. А это значит, что ПД вплоть до начала кризиса, вызванного пандемией короновируса, являлись эксклюзивным каналов для ввода ликвидности в систему.

Этот ввод осуществляется через покупку Федеральной системой гособлигаций и ипотечных бумаг. После этого ПД практически уже не связаны никакими обязательствами, кроме участия в торгах, организуемых каждую неделю Казначейством, и могут тратить полученные средства по своему усмотрению. Единственным ограничением здесь являются нормативы резервирования, поскольку полученные первичными дилерами средства оседают на их резервных счетах в ФРС.

Следует отметить, что Федрезерв пользуется почти исключительно операциями на открытом рынке для управления своими активами в той части, которая касается резервов банковской системы. Соответствующий раздел баланса носит название счета системы открытых рынков. Весьма важно показать, как через изменения в балансе Федрезерва организована процедура делания денег «из воздуха». В момент покупок ценных бумаг происходит прирост активов по статьям казначейских ценных бумаг и ипотечных ценных бумаг. Одновременно происходит эквивалентное увеличение пассивов по субстатье “Designated Financial Market Utilities” (статья "Others deposits"), которая отражает финансовые услуги специально назначенных субъектов. А этими субъектами, в свою очередь, являются ПД, и через неделю

3 Последние имеющиеся данные по состоянию на начало 2016 года 
средства попадают уже непосредственно на их счета в Федеральной системе, которые учитываются по статье пассивов"Depository institutions".

Таким образом, появление новых долларов происходит через увеличение средств "Designated Financial Market Utilities", при этом увеличение баланса Федрезерва сопровождается направлением ликвидных средств в американскую банковскую систему. Но эта процедура осуществляется не напрямую, а через посредство ПД, т.е. формально ФРС ограничивается тем, что покупает ценные бумаги у этих, специально назначенных компаний. Далее Федрезерв по большому счету никак не влияет на операции первичных дилеров. При этом, очень важно, что первичные дилеры, находясь в тесном контакте и с ФРС, и с Казначейством, получают возможность реально влиять на цены правительственных ценных бумаг, т.е. они по сути становятся market makers на важнейшем сегменте мировых финансовых рынков - рынке правительственных ценных бумаг, или трэжерис. Но и это еще не все. Получая в свое распоряжение колоссальные средства, ПД могут без всяких проблем манипулировать американским фондовым рынком, играя главным образом на повышение, и генерировать при этом огромные прибыли.

О роли первичных дилеров свидетельствует и ситуация, сложившаяся в сфере кредитно-денежной политики в начале 2019 года. После относительно недолгого периода ужесточения ФРС вновь обратилась к политике снижения ключевых ставок. Некоторые эксперты называют одной из основных причин обозначившихся в тот период сдвигов резкое ухудшение финансового положения именно первичных дилеров ФРС. Игра на повышение, которую они вели все предшествовавшие годы, привела к тому, что в их активах скопилось значительное количество казначейских облигаций. Однако в условиях возросшего предложения со стороны американского Казначейства (в среднем 100 млрд. долл. в месяц) и осуществления программы «нормализации» вплоть до начала 2019 года (ежемесячное предложение на сумму в 50 млрд. долл.) на фоне одновременного падения спроса из-за недостаточной активности иностранных ЦБ и американской банковской системы указанные инструменты должны были дешеветь.

В момент, когда падение цен на трэжерис достигло некоего предела, ПД столкнулись с риском острой нехваткой ликвидности, что должно было заставить их в условиях падающего рынка срочно избавляться от длинных позиций, в т.ч. для выкупа фьючерсов, которые были приобретены для хеджирования длинных позиций. И это могло обернуться для многих из них крахом. Спасти положение смог лишь разворот в сторону смягчения денежной политики с последующей накач- кой рынков ликвидностью опять же исключительно через ПД. Основным источником этих средств смог стать только Федрезерв в ассоциации с другими ведущими центробанками мира. И такой разворот произошел в начале 2019 года, т.е. наблюдалась если не причинно-следственная связь, то по крайней мере корреляция между потребностями первичных дилеров и сдвигами в денежной политике ФРС.

При этом в поддержку мнения о решающем влиянии ПД на формирование денежной политики можно подвести и историческое обоснование. Так, многие американские специалисты считают, что прежде всего неверное позиционирование ПД в 2007-2008 гг. на рынке гособлигаций, а не ошибки Леман-Бразерс стало главной причиной обвала в сентябре-октябре 2008 года. А двумя годами позже ФРС, не преуспев в спасении ПД в рамках обычно применяемых тогда инструментов, обратилась к программе количественного смягчения (QE), основную пользу из которой извлекли именно ПД.

Данная интерпретация ситуации с денежной политикой может показаться недостаточно обоснованной, однако она наталкивает на важное умозаключение. Рассматривая первичных дилеров как верхушку глобального финансового сектора, можно заметить органически присущую ему склонность содействовать постоянному расширению денежной массы, дальнейшему наращиванию экспорта доллара в обмен на импорт товаров и услуг, стремление поставить под свой контроль операции на глобальных финансовых рынках.

В этом контексте сопоставление данных об операциях Федрезерва на открытых рынках с данными о динамике индекса S\&P 500 позволяет предположить, что создание ликвидности напрямую влияет на рост указанного индекса. Таким образом, позитивная динамика американского фондового рынка по крайней мере в период после 2008 года была обусловлена прежде всего операциями ПД, которые де-факто осуществляли функцию реализации денежной политики США.

Очень важным моментом является то, что в «накачке» американского фондового рынка заметное участие принимают и некоторые другие ЦБ, которые, по всей видимости, в значительной мере согласовывают свою денежную политику с ФРС. Речь идет главным образом о пяти крупнейших центробанках, с которыми у ФРС заключено соглашение о неограниченном обмене в рамках валютного свопа (ЕЦБ, Банк Англии, Банк Японии, Национальный банк Швейцарии, банк Канады). Данные рисунка 1 демонстрируют взаимосвязь эмиссии ключевых валют и динамики американского фондового рынка. Получается, что в период с 2009 по 2017 годы динамика индекса S\&P Index практически совпадала с динамикой 


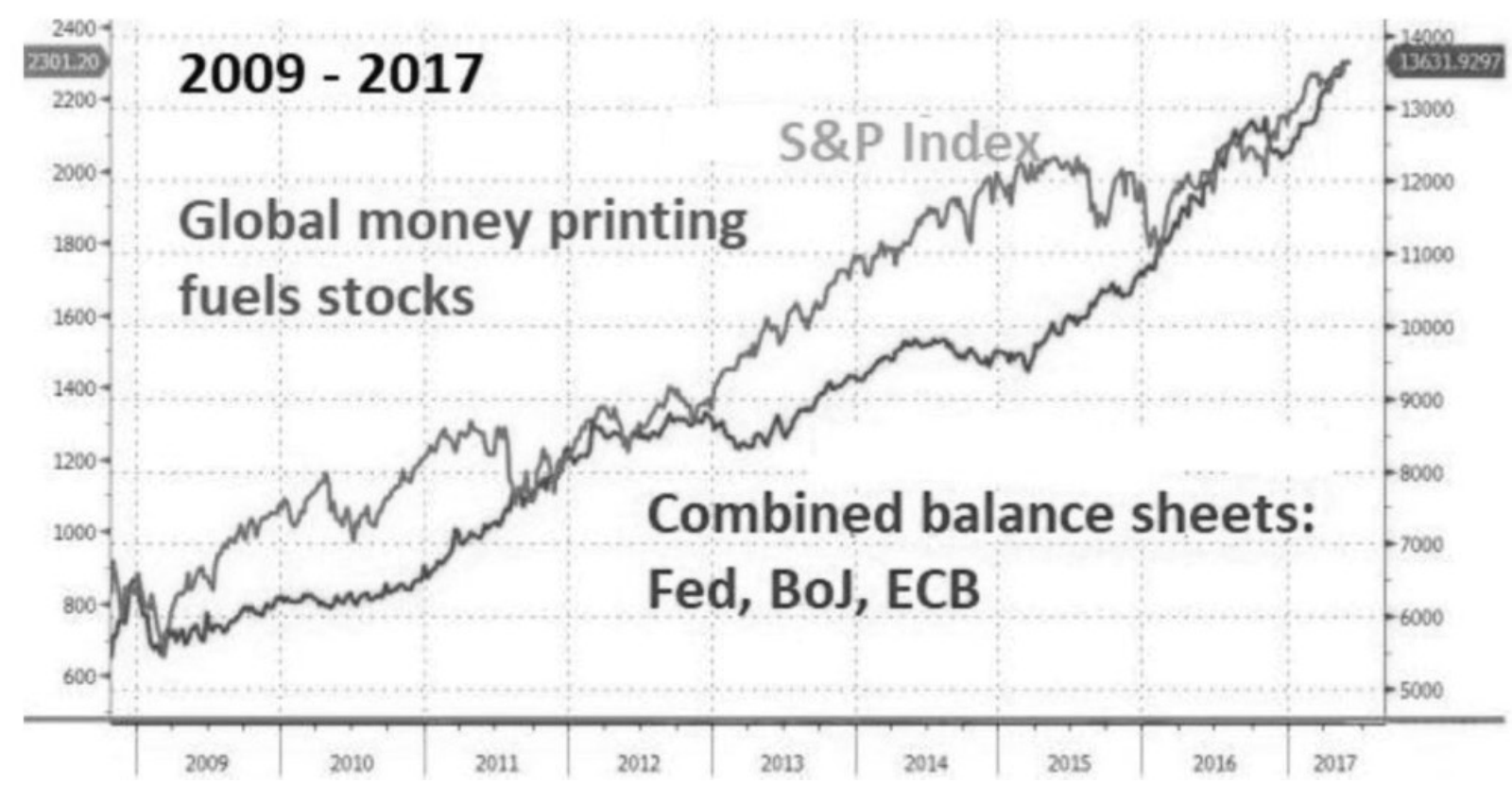

Рис. 1. Сравнительная динамика изменения индекса S\&P Index и суммарной валюты баланса ФРС, ЕЦБ и Банка Японии (2).

изменений суммарной валюты баланса трех ключевых центральных банков мира: Федеральной резервной системы, Европейского центрального банка и Банка Японии.

В свою очередь, данные о динамике денежного агрегата (M2) в этих странах за последние 15 лет подтверждают тезис о практически о скоординированной политике их ЦБ, причем в США Федрезерв увеличил в течение 10 недель (с марта по май 2020 года) величину денежного агрегата M2 на 2,25 трлн. долл. С точки зрения скорости наращивания денежной массы это оказалось абсолютным рекордом. Почти столь же стремительно выросла и денежная масса в странах еврозоны и в Японии.

В целом факт картельного сговора между ведущими центробанками не вызывает сомнения, но формально только соглашение о овалютном свопе может в какой-то мере свидетельствовать о правильности этого предположения. В то же время сам масштаб этих операций может рассматриваться в качестве дополнительного довода в его пользу: по состоянию на 31 марта 2020 года активы ФРС по статье "Central bank liquidity swaps" составили около 356 млрд. долл., или более 6\% всех активов ФPC (4)

Возвращаясь к развороту денежной политики, который произошел в начале 2019 года, отметим, что в течение нескольких месяцев ситуация внешне оставалась спокойной, и Федрезерв ограничивался снижением ключевых ставок. Но затем наступил сентябрь 2019 года, и некие глубинные сдвиги заставили американский истеблишмент совершенно неожиданно обратиться к экстренным мерам по управлению глобальными финансами - практически начать их перевод на мобилизационные рельсы. То, что стартовало 17 сентября и продолжается до сих пор, можно сравнить лишь с ситуацией во времена Второй мировой войны, когда ФРС и Казначейство США заключили соглашение об обеспечении максимально дешевого финансирования расходов военного времени. Соглашение действовало с 1942 по 1951 год. Де-факто два конкурирующих института вынуждены были сплотиться перед лицом опасности, носившей экзистенциальный характер, причем Федрезерв намеренно пошел на временное ограничение своей независимости.

По мнению бывшего конгрессмена и кандидата в президенты США, а также ярого противника Федрезерва Рона Пола (Ron Paul), 17 сентября стало значимой датой В экономической истории США (9). Что же произошло 17 сентября 2019 года? Именно в этот день Федеральный банк Нью-Йорка начал экстренные денежные вливания на рынке репо после того, как процентные ставки на межбанковском рынке в 10 раз превысили целевую ставку ФРС.

Операции ФРС на рынке репо не прекращаются до настоящего времени. Они лишь нарастают. По данным за первый квартал 2020 года, баланс этих операций увеличился с 337 млрд. долларов по состоянию на 31 декабря 2019 года до 569 млрд. долларов по состо- 

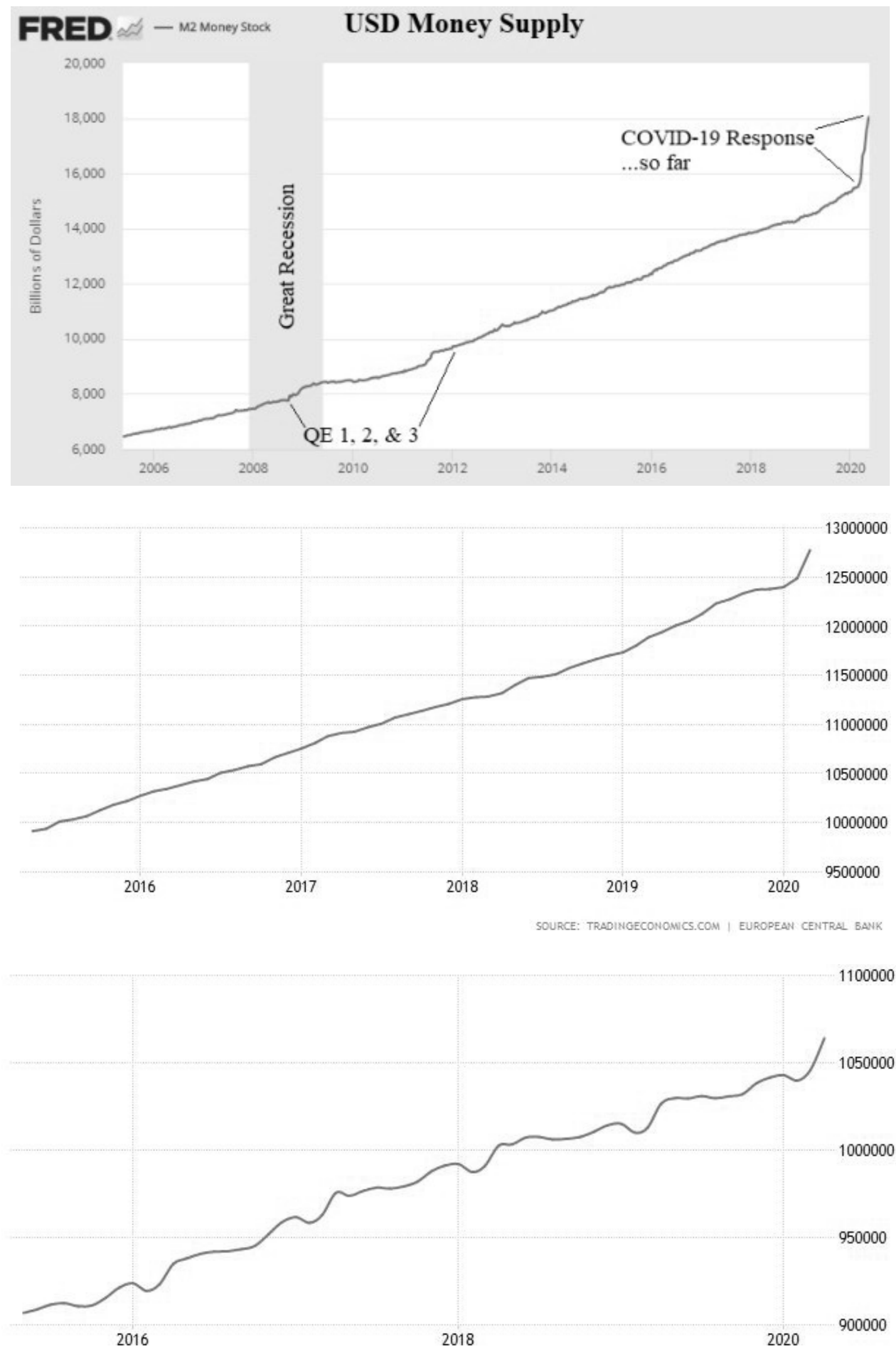

SOURCE: TRMDINGECONOMICS.COM | BANK OF JAPAN

Рис. 2. Динамика денежной массы (M2) в США, еврозоне и Японии за период с 2006 по 2020 гг. (5) 


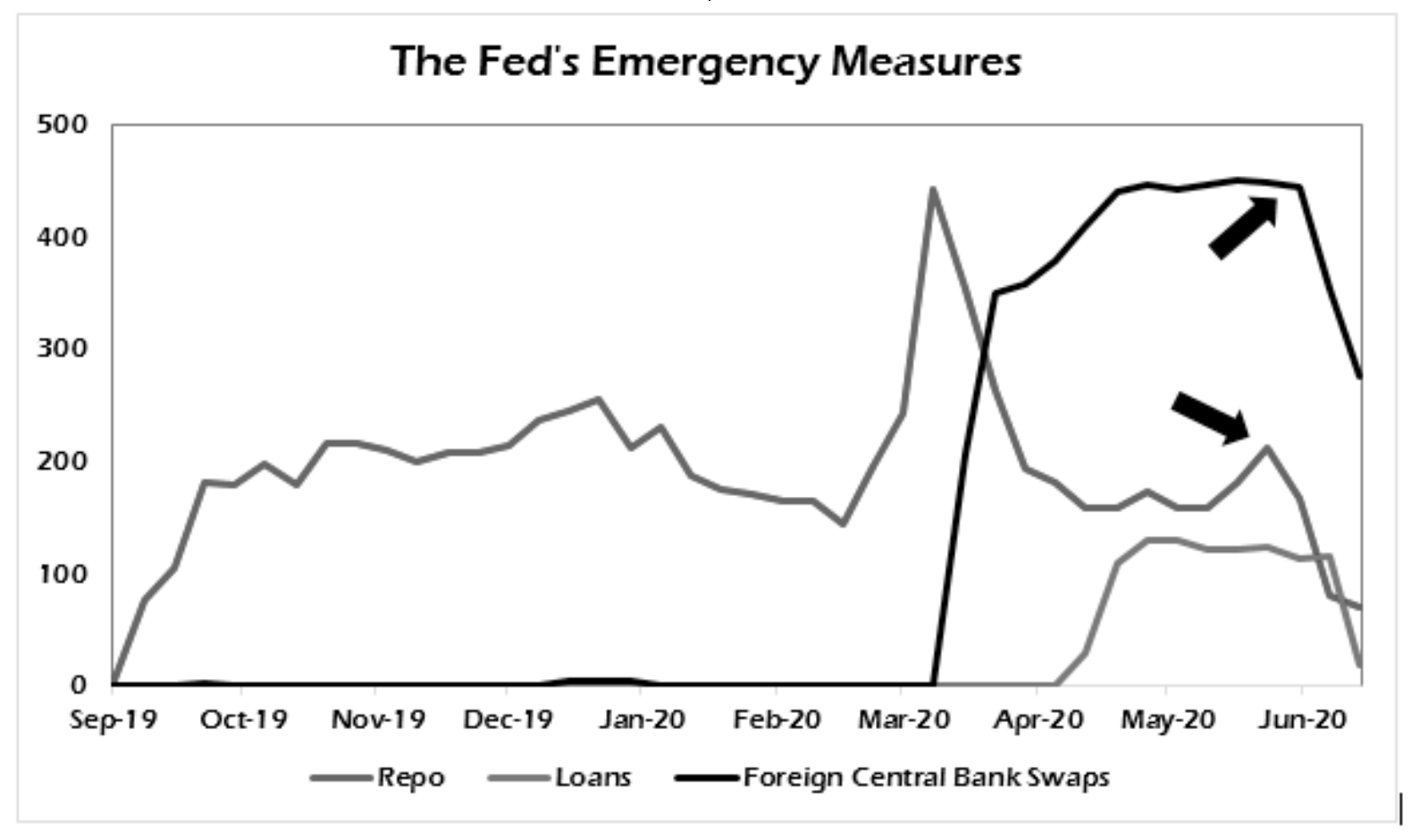

Рис. 3. Чрезвычайные меры, предпринимаемые ФРС в период с сентября 2019 по июнь 2020 года (6)

янию на 31 марта 2020 года (???). Эти операции иногда называют количественным смягчением «на стероидах», но затем Федрезерв приступил и к классическому QE. За первый квартал 2020 года суммарные активы ФРС по статьям «Казначейские ценные бумаги» и «Федеральные и гарантированные Правительством ипотечные ценные бумаги» увеличились с 3849 млрд. долларов до 4910 млрд. долларов, т.е. на 28\%. Всего же валюта баланса Федрезерва увеличилась с 4174 млрд. долларов до 5743 млрд. долларов. При этом процентные ставки ФРС приближаются к нулю.

Но и это еще не все. Если скупка федеральных и гарантированных Правительством ценных бумаг, которая осуществляется через посредство первичных дилеров, остается в рамках законодательства, то следующий шаг - скупка «мусорных» бумаг корпораций и местных властей выходит за эти рамки. Тем не менее подобное решение было принято уже в апреле 2020 года, и речь здесь идет об очередной беспрецедентной сумме в 2,3 трлн. долларов. Эти средства должны распределяться в виде кредитов, которые с высокой степенью вероятности в основном погашены не будут. Для того, чтобы как-то легализовать эти операции была придумана схема, в соответствии с которой выкупом инструментов занимается не ФРС, а Казначейство с использованием Фонда валютной стабилизации (Exchange Stabilization Fund), находящегося в ведении руководителя Казначейства. В свою очередь, Федрезерв будет открывать специальные кредитные линии под каждую операцию, т.е. выступать в качестве источника финансирования. Управлять закупками и администрировать эти специальные линии будет нанятая Федрезервом крупнейшая в мире инвестиционная группа BlackRock во главе с Ларри Финком (Larry Fink).

По мнению американского финансового эксперта Тома Луонго (Tom Luongo), федеральное правительство таким образом национализирует значительные участки финансовых рынков. ФРС предоставляет для этого деньги, a BlackRock будет осуществлять собственно сделки (8). И это, по мнению того же Луонго, ничто иное как воплощение в жизнь в чистом виде «Современной денежной теории» (Modern Monetary Theory - ММT): Федрезерв создает из ничего деньги, покупая на них у Казначейства долги, которые никогда не будут продаваться, а Правительство делает с полученными деньгами все, что хочет, привлекая при этом в виде распорядителя средств BlackRock.

Можно предположить, что для реализации этого плана глобальному истеблишменту понадобилось нечто вроде дымовой завесы. В сентябре 2019 год КОВИД-19 еще не стоял на повестке дня, и создается впечатление, что первоначально главную роль должна была сыграть раскрутка т.н. «зеленой» повестки дня. Именно эта тематика оказалась в центре внимания Давосского форума в январе 2020 года. Среди различных мер было пред- 
ложено сделать проблему изменения климата одним из приоритетов в деятельности центральных банков по всему миру. Кроме того, риски, связанные с изменением климата, были причислены к важнейшим финансовым рискам, а для конкретизации необходимых подходов было предложено использовать рамки Task Force on Climate related Financial Disclosures (TCFD), созданной в 2015 году Банком международных расчетов в кооперации с Управлением финансовой стабилизации (Financial Stability Board - инструмент Группы 20). Характерно, что одной из основательниц TCFD является уже упоминавшаяся группа BlackRock во главе с Ларри Финком, именно который и обратил внимание на необходимость привлечь данную структуру к оценке связанных с изменением климата рисков (3).

Впрочем, «зеленая» повестка дня несколько отошла на второй план после того, как началась эпидемия Ковид19, переросшая в марте в пандемию. Наиболее масштабные шаги по переформатированию финансовых рынков были предприняты ФРС уже в контексте распространения короновируса. Таким образом, денежные власти сумели воспользоваться сложившейся ситуацией в своих интересах. Получается, что в глобальной финансовой системе произошло нечто, что потребовало со- вершенно беспрецедентных мер, и на первые позиции в их разработке и реализации выдвинулись не просто представители крупнейших мировых банков, которые до сих пор ассоциировались с акционерами ФРС, а представители крупнейших инвестиционных групп, таких как BlackRock, Vanguard Funds, Fidelity Investments, State Street Global, Goldman Sachs. В то же время рисунок 3 свидетельствует о том, что интенсивность чрезвычайных мер с выходом из пандемии снизилась, что, однако, пока еще не дает оснований считать это серьезным трендом.

В заключение следует отметить, что приведенные соображения отражают лишь один, хотя и достаточно вероятный, вариант оценки деятельности ФРС. Существуют и другие подходы, в рамках которых роль Федрезерва как института либо сильно принижается, вплоть до того, что он якобы ничего не решает, либо, наоборот, рассматривается излишне позитивно в плане влияния не только на экономику США, но и на глобальную экономику в целом. В любом случае нельзя отрицать те во многом драматические изменения, которые произошли в деятельности Федеральной резервной системы за еще неполный год, которые нашли отражение прежде всего в монетизации федерального долга и беспрецедентном усилении государственного контроля за финансовыми рынками.

\section{ЛИТЕРАТУРА}

1. К Катасонов В. Ю. Золото в мировой и российской истории XIX-XXI ВB. - М.: Издательство «Родная страна», 2017. — 448 стр.

2. Lee, Adler. How the FED Controls the Stock Market. The Sure Money Investor. URL: http://suremoneyinvestor.com/opportunity-reports/how-the-fed-controls-thestock-market/ дата обращения 26.07.2018

3. F. William Engdahl. Follow the Real Money Behind the New Green Agenda. NE0 New Eastern Outlook, 27.01.2020, URL: https://journal-neo.org/2020/01/27/followthe-real-money-behind-the-new-green-agenda/ Дата обращения 01.02.2020

4. Federal Reserve Banks Combined Quarterly Financial Report, March 2020, URL: https://www.federalreserve.gov/aboutthefed/files/quarterly-report-20200528.pdf/ дата обращения 28.06.2020.

5. Get Ready for Gold's Hyper-Bull, Luke Burgess 03/07/2020, URL: https://www.energyandcapital.com/editors/luke-burgess?utm_optipub=email-article\&identifier $=e 578 \mathrm{~d} 7 \mathrm{bffd} 2 \mathrm{c75} \mathrm{cdb}$ 42e0e44222a68a8\&utm_referrer=3/ дата 0бращения 04.07.2020

6. Gold Will Flourish in the Worst US Political Landscape in 160 Years Posted by Tom Luongo | Jun 26, 2020 | Investing, URL: https://moneyandmarkets.com/goldprices-marching-toward-2k/?post_ids=22749\%2C22558\%2C22365\%2C22174\%2C22020\&utm_source=MAM-Newsletter\&utm_medium=Email\&utm_ campaign=Daily-Article-Traffic\&bsft_eid=a580b1f7-e3e0 -4 be5-93e7-7d390ff85b79\&utm_content=062820_mam_weekly\&bsft_clkid=e70c543bc40f-40e6-a600-8c59c25bbda6\&bsft_uid=48772213-7abe-4cd3-840f-12d3fd4e022f\&bsft_mid=9b617cb5-10d2-4ed2-8145-466729b1fecb\&bsft_ utid=48772213-7abe-4cd3-840f-12d3fd4e022f-M0NMARW\&bsft_link_id=100\&bsft_ek=2020-06-28T12\%3A50\%3A54Z\&bsft_mime_type=html/ дaтa обращения 30.06 .2020

7. Shah, Gilani. How We Can Stop the Globalization That's Bleeding Us Dry. Money Morning, May 27, 2017. URL: https://moneymorning.com/2017/05/27/how-we-canstop-the-globalization-thats-bleeding-us-dry/ дата обращения 30.07.2018

8. Luongo: Gold Soars as the Fed Goes Full MMonTy Posted by Tom Luongo |Apr 10, 2020| Investing URL: https://moneyandmarkets.com/gold-soars-as-the-fed-goesfull-mmonty-tom-luongo/ дата обращения 30.05.2020.

9. Ron Paul: Can the Fed Save Us From Climate Change?

10. Posted by Money and Markets Staff | Mar 3, 2020 | News, URL: https://moneyandmarkets.com/?p=19084?post_ids=18604,18204,17971,17773,17619\&utm_ source=MAM-Newsletter\&utm_medium=Email\&utm_campaign=Daily-Article-Traffic/ дата обращения 30.05 .2020 